\title{
Thyroid Lymphoepithelial Cysts Mimicking Calcified or Solid Nodules on Ultrasonography
}

\section{(ㄷ) (i) (ㅇ) $\ominus$}

\author{
Authors \\ Yukie Tsutsuura', Mitsuyoshi Hirokawa², Ayana Suzuki', Hisashi Ota1', Maki Oshita', Mitsuhiro Fukushima ${ }^{3}$, \\ Kaoru Kobayashi ${ }^{3}$, Akira Miyauchi ${ }^{3}$
}

\author{
Affiliations \\ 1 Kuma Hospital, Department of Clinical Laboratory, Kobe, \\ Japan \\ 2 Kuma Hospital, Department of Diagnostic Pathology and \\ Cytology, Kobe, Japan \\ 3 Kuma Hospital, Department of Surgery, Kobe, Japan
}

Key words

thyroid, ultrasound, lymphoepithelial cyst, calcification

$\begin{array}{ll}\text { received } & 02.08 .2018 \\ \text { revised } & 09.03 .2019 \\ \text { accepted } & 22.05 .2019\end{array}$

Bibliography

DOI https://doi.org/10.1055/a-0943-6553

Ultrasound Int Open 2019; 5: E60-E64

(c) Georg Thieme Verlag KG Stuttgart · New York

ISSN 2199-7152

Correspondence

Ms. Yukie Tsutsuura

Kuma Hospital,

Department of Clinical Laboratory,

8-2-35, Shimoyamate-dori,

Chuo-ku, Kobe

650-0011

Japan

Tel.:+81/78/371 3721, yke.llob337@gmail.com

\section{ABSTRACT}

Purpose Thyroid lymphoepithelial cysts (TLECs) are rare, and detailed ultrasonography (US) findings have not been reported. This study aimed to examine in detail the US findings for 32 TLECs and to clarify the diagnostic problems associated with them.

Materials and Methods We examined 32 TLECs resected from 21 patients at the Kuma hospital between January 2008 and April 2018. All patients underwent US before resection. From the patients' medical records, we retrospectively assessed US reports and photographs of TLECs.

Results The following four types of TLECs were classified: cystic, mixed solid and cystic, pseudo-solid, and pseudo-calcified types. The incidences were $50.0 \%, 12.5 \%, 12.5 \%$, and $25.0 \%$, respectively. Among the four types, pseudo-calcified TLECS were the smallest in size (mean: $7.1 \mathrm{~mm}$ ). Of 24 nodules that had been interpreted in US reports, $11,9,1,2$, and 1 were benign, very low, low, intermediate, and high, respectively. Calcification and intramural solid growth were not identified by histological examination.

Conclusion We should be aware that approximately half of TLECs do not exhibit US appearances typical of simple cysts, and TLECs may mimic calcified or solid nodules on US, although the reason remains unknown.

\section{Introduction}

Thyroid lymphoepithelial cysts (TLECs) are rare lesions that are histologically lined by stratified squamous epithelia or ciliated columnar cells with dense aggregates of lymphoid tissue beneath the epithelial lining [1-6]. TLECs are usually associated with Hashimoto's thyroiditis [2, 7-9]. There are only a few reports describing the ultrasonography (US) findings in TLECs [4, 5, 9-11]. According to these reports, TLECs do not exhibit the sonographic appearance of simple cysts, which are generally characterized by an anechoic lesion with thin walls and posterior enhancement deep to the posterior capsule $[4,11]$. Suzuki et al. reported that half of TLECs are interpreted as calcified nodules, despite the nodules themselves having no calcification [2]. Kwak et al. reported a case of TLEC mimicking malignancy on US [11]. Because of the rarity of TLECs, detailed US findings for TLECs have thus far not been reported. The present study aimed to examine the US findings for 32 TLECs in detail and to clarify diagnostic problems.

\section{Materials and Methods}

We reviewed the pathology of thyroid specimens resected at the Kuma hospital between January 2008 and April 2018, and extract- 
ed data of 36 patients with TLECs confirmed by pathological examination. The diagnosis of TLEC was microscopically defined as an intrathyroidal cyst composed of non-neoplastic squamous cells associated with dense lymphocytic infiltration at the periphery of the cyst wall. There were no lymphoepithelial cysts lined by ciliated columnar cells. We excluded cysts located in the isthmus because these could have been thyroglossal duct cysts.

We retrospectively examined the tissue samples and analyzed the US reports and photographs that were obtained from patients' medical records at the Kuma hospital. US was performed using the APLIO 80 SSA-770A (Toshiba Medical Systems Co., Ltd., Otawara, Japan) or APLIO 500 TUS-A500 (Toshiba) with the PLT-805AT
(Toshiba) or PLT-1005BT (Toshiba) probe. US reports with photographs were available in 21 of 36 patients. As some patients had multiple TLECs, a total of 32 TLECs in 21 patients were ultimately included in this study.

All of the patients underwent thyroidectomy: 16 for malignant neoplasm, 2 for adenomatous goiter, 2 for Graves' disease, and 1 for Hashimoto's thyroiditis. No patient underwent thyroidectomy for resection and/or diagnosis of TLEC. In 6 patients with multiple TLECs, each cyst was separately evaluated. Of 32 TLECs, 16 had previously been reported by Suzuki et al. [2].

- Table 1 Ultrasound findings in 32 thyroid lymphoepithelial cysts.

\begin{tabular}{|c|c|c|c|c|c|c|}
\hline \multirow{2}{*}{\multicolumn{2}{|c|}{ Types, n (\%) }} & Cystic & Mixed solidn and cystic & Pseudo-solid & Pseudo-calcified & Total \\
\hline & & 16 (50.0\%) & $4(12.5 \%)$ & 4 (12.5\%) & $8(25.0 \%)$ & $32(100 \%)$ \\
\hline \multicolumn{2}{|l|}{ Mean size $(\mathrm{mm})$} & 23.6 & 16.5 & 8.5 & 7.1 & 16.7 \\
\hline \multicolumn{2}{|l|}{ (range) } & $(7-64)$ & $(8-37)$ & $(5-13)$ & $(3-12)$ & $(3-64)$ \\
\hline \multirow[t]{4}{*}{ Shape } & Round & $12 / 14$ & $1 / 2$ & $3 / 4$ & $\mathrm{NI}$ & $16 / 20$ \\
\hline & Spindled & $2 / 14$ & $1 / 2$ & $0 / 4$ & $\mathrm{NI}$ & $3 / 20$ \\
\hline & Irregular & $0 / 14$ & $0 / 2$ & $1 / 4$ & $\mathrm{NI}$ & $1 / 20$ \\
\hline & Taller than wide & $3 / 14$ & $0 / 2$ & $0 / 4$ & $\mathrm{NI}$ & $3 / 20$ \\
\hline \multirow[t]{5}{*}{ Margin } & Smooth & $16 / 16$ & $4 / 4$ & $3 / 4$ & $3 / 8$ & $26 / 32$ \\
\hline & Irregular & $0 / 16$ & $0 / 4$ & $1 / 4$ & $5 / 8$ & $6 / 32$ \\
\hline & Well-defined & $16 / 16$ & $4 / 4$ & $2 / 4$ & $5 / 8$ & $27 / 32$ \\
\hline & III-defined & $0 / 16$ & $0 / 4$ & $1 / 4$ & $2 / 8$ & $3 / 32$ \\
\hline & Hypoechoic rim & $0 / 16$ & $0 / 4$ & $1 / 4$ & $0 / 8$ & $1 / 32$ \\
\hline \multirow[t]{4}{*}{ Echogenicity } & Anechoic & $11 / 16$ & $0 / 4$ & $0 / 4$ & $\mathrm{NI}$ & $11 / 24$ \\
\hline & Hypoechoic & $0 / 16$ & $0 / 4$ & $3 / 4$ & $\mathrm{NI}$ & $3 / 24$ \\
\hline & Isoechoic & $5 / 16$ & $4 / 4$ & $1 / 4$ & $\mathrm{NI}$ & $10 / 24$ \\
\hline & Hyperechoic & $0 / 16$ & $0 / 4$ & $0 / 4$ & $\mathrm{NI}$ & $0 / 24$ \\
\hline \multicolumn{2}{|c|}{ Suspended internal debris } & $5 / 16$ & $1 / 4$ & $\mathrm{NI}$ & $\mathrm{NI}$ & $6 / 20$ \\
\hline \multicolumn{2}{|l|}{ Comet-tail artifacts } & $0 / 16$ & $0 / 4$ & $0 / 4$ & $\mathrm{NI}$ & $0 / 24$ \\
\hline \multicolumn{2}{|l|}{ Fluidity on Doppler } & $8 / 15$ & $2 / 3$ & $1 / 4$ & $\mathrm{NI}$ & $11 / 22$ \\
\hline \multicolumn{2}{|c|}{ Posterior echo enhancement } & $6 / 16$ & $1 / 4$ & $0 / 4$ & $\mathrm{NI}$ & $7 / 24$ \\
\hline \multirow[t]{2}{*}{ Vascular flow sign } & Peri-nodular & $0 / 15$ & $0 / 3$ & $0 / 3$ & $\mathrm{NI}$ & $0 / 21$ \\
\hline & Intra-nodular & $0 / 15$ & $0 / 3$ & $1 / 3$ & $\mathrm{NI}$ & $1 / 21$ \\
\hline \multirow{6}{*}{$\begin{array}{l}\text { Original ultrasound } \\
\text { report }\end{array}$} & High & $0 / 16$ & $0 / 4$ & $1 / 4$ & $0 / 8$ & $1 / 32$ \\
\hline & Intermediate & $0 / 16$ & $0 / 4$ & $2 / 4$ & $0 / 8$ & $2 / 32$ \\
\hline & Low & $0 / 16$ & $0 / 4$ & $1 / 4$ & $0 / 8$ & $1 / 32$ \\
\hline & Very low & $5 / 16$ & $4 / 4$ & $0 / 4$ & $0 / 8$ & $9 / 32$ \\
\hline & Benign & $11 / 16$ & $0 / 4$ & $0 / 4$ & $0 / 8$ & $11 / 32$ \\
\hline & $\mathrm{NI}$ & $0 / 16$ & $0 / 4$ & $0 / 4$ & $8 / 8$ & $8 / 32$ \\
\hline \multirow{4}{*}{$\begin{array}{l}\text { Histological } \\
\text { examination }\end{array}$} & Squamous cell & $16 / 16$ & $4 / 4$ & $4 / 4$ & $8 / 8$ & $32 / 32$ \\
\hline & Ciliated columnar cell & $0 / 16$ & $0 / 4$ & $0 / 4$ & $0 / 8$ & $0 / 32$ \\
\hline & Calcification & $0 / 16$ & $0 / 4$ & $0 / 4$ & $0 / 8$ & $0 / 32$ \\
\hline & Hashimoto's disease & $16 / 16$ & $3 / 4$ & $4 / 4$ & $8 / 8$ & $31 / 32$ \\
\hline
\end{tabular}

NI: Not interpreted 

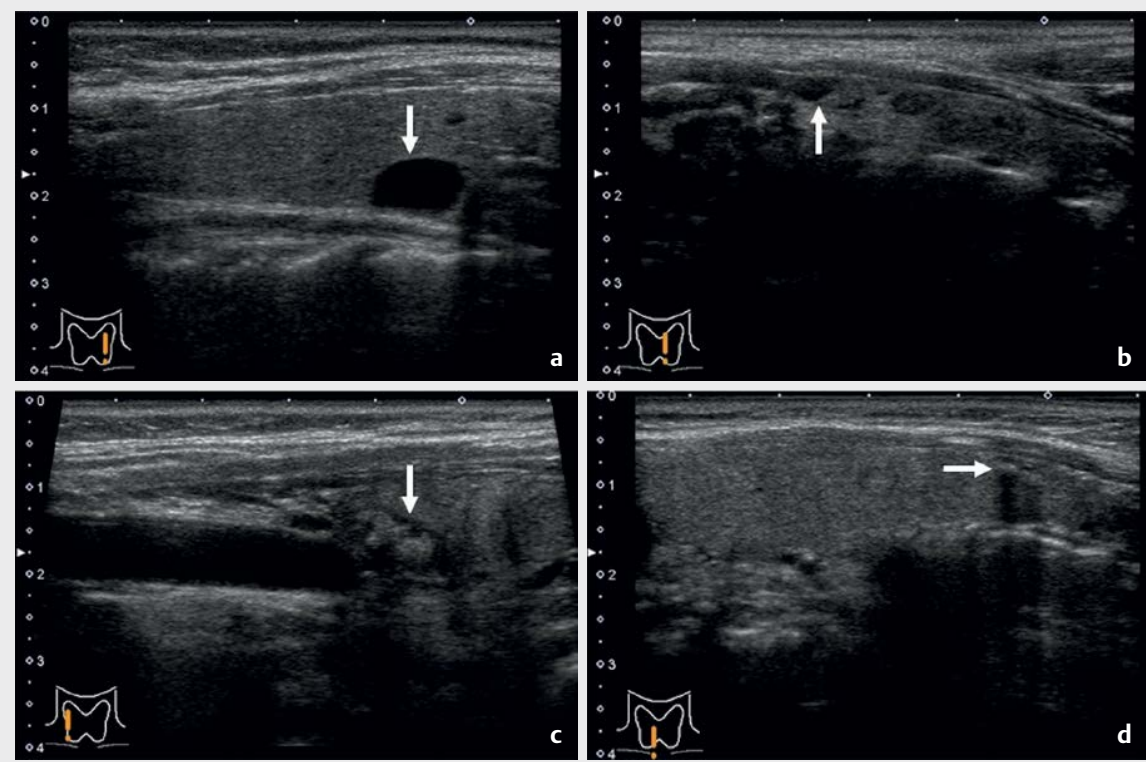

Fig. 1 Ultrasonography of the four types of thyroid lymphoepithelial cysts (arrows). a: Cystic type, b: Mixed solid and cystic type, c: Pseudo-solid type, d: Pseudo-calcified type. (B-mode, longitudinal view).

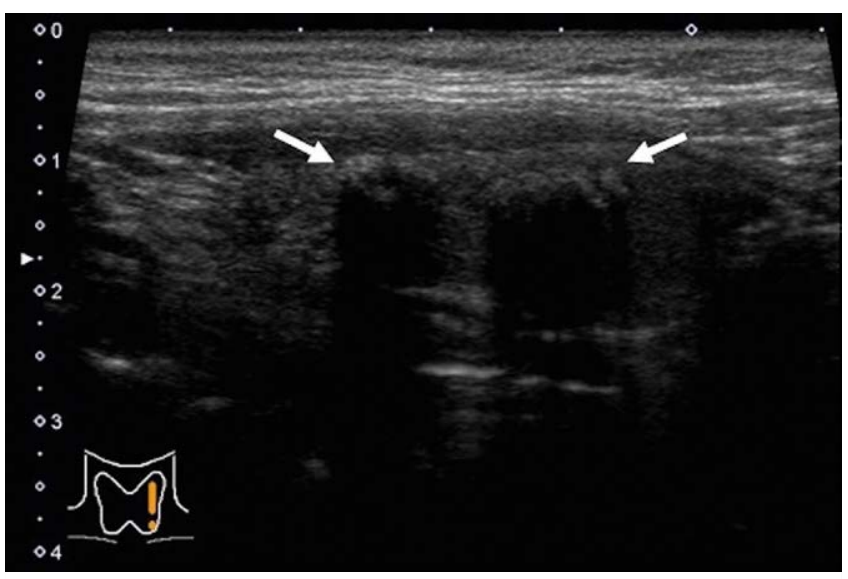

- Fig. 2 Ultrasonography of thyroid lymphoepithelial cysts (arrows), pseudo-calcified type. The nodules show the hyperechoic irregular margin and posterior shadowing artifact. (B-mode, longitudinal view).

\section{Results}

- Table 1 shows the US findings for 32 thyroid lymphoepithelial cysts. We classified four types of US findings for TLECs: cystic ( $>$ Fig. 1a), mixed solid and cystic ( $\triangleright$ Fig. 1b), pseudo-solid ( $\triangleright$ Fig. 1C), and pseudo-calcified type ( $\vee$ Fig. 1d), and these were defined as nodules with $>80 \%$ cystic component, nodules with $>20 \%$ and $<80 \%$ cystic component, nodules with $>80 \%$ solid component, and nodules with a hyperechoic rim and posterior acoustic shadowing, respectively. Among the four types, the cystic type was the most frequently observed type (50.0\%), followed by pseudo-calcified (25.0\%), pseudo-solid (12.5\%), and mixed solid and cystic (12.5\%) types. The cystic type had the largest mean size $(23.6 \mathrm{~mm})$, and the pseudo-calcified type was the smallest $(7.1 \mathrm{~mm})$. Most of the nodules were mostly round and well-defined, and the margin was smooth, except the pseudo-calcified nodules. In 5 of 8 pseudo-calcified nodules, the margin was irregular ( $>$ Fig. 2 ). Three nodules exhibited a "taller than wide" shape. On internal echogenicity, 11 (45.8\%), 3 (12.5\%), and 10 (41.7\%) were anechoic ( Fig. 1a), hypoechoic, and isoechoic ( $\mathbf{F i g . ~ 1 b , ~}>$ Fig. 3), respectively. $\ln 5$ (31.3\%) of 16 cystic types, the focal solid areas were isoechoic. 6 of 20 nodules with a cystic area exhibited suspended internal debris (> Fig. 4). Comet-tail artifacts were not observed. On Doppler US, intranodular vascular flow indicating liquid was observed in 1 pseudo-solid nodule ( $\triangleright$ Fig. 5 ).

Of 24 nodules that were interpreted in US reports, 11, 9, 1, 2, and 1 were benign, very low, low, intermediate, and high, respectively. Microscopically, the cysts were mainly unilocular, although some were multilocular. The cysts contained proteinaceous material, cell debris, and/or cholesterol clefts. No nodules revealed intramural solid growth or calcified material. In all 9 nodules with fine needle aspiration cytology, there was no indication that the insertion of the needle was disturbed by hardness or resistance.

\section{Discussion}

In this study, we examined the US findings for 32 TLECs in detail and clarified the diagnostic problems associated with them. On US, simple thyroid cysts are well-defined, round, thin-walled anechoic nodules with smooth margins [12] and are frequently associated with posterior echo enhancement [13]. Suspended fine internal debris and comet-tail artifacts may be observed $[14,15]$. When pressure is applied on the mass by the probe, the contents may shift [4], and the fluidity may be identified by compression on Doppler [15]. 


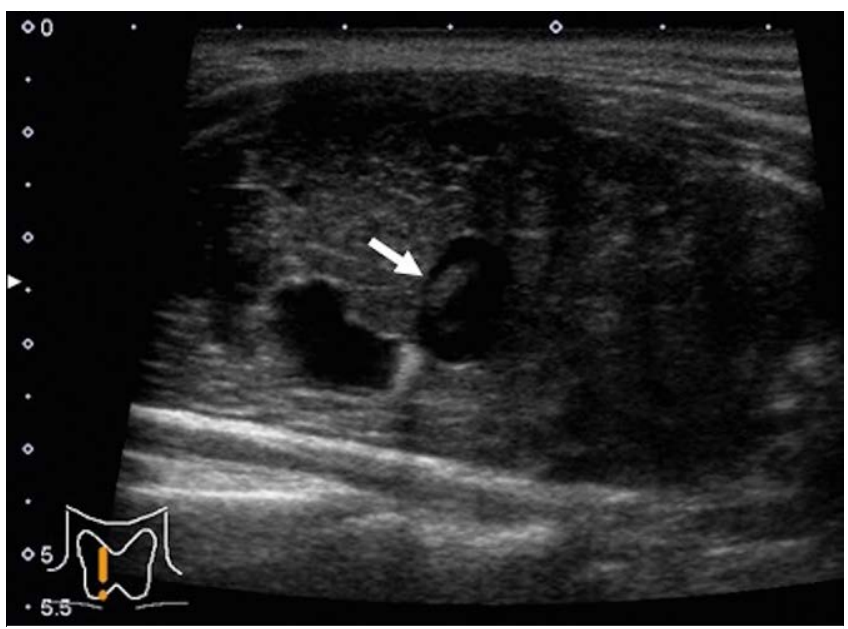

- Fig. 3 Ultrasonography of a thyroid lymphoepithelial cyst, cystic type. The nodule contains an isoechoic solid lesion (arrow). (B-mode, longitudinal view).

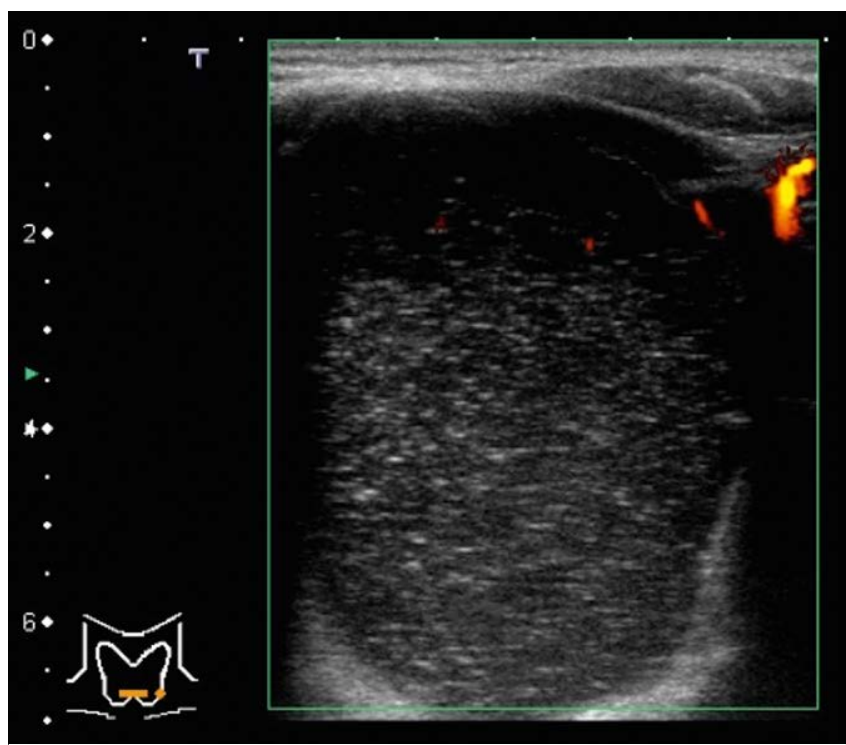

- Fig. 4 Ultrasonography of a thyroid lymphoepithelial cyst, cystic type. The cyst contains suspended internal debris. The intranodular vascular flow indicates liquid. (Color Doppler image of B-mode, horizontal view).

TLECs are generally unilocular cysts with thin walls, and are not associated with intramural nodules [2]. Therefore, US findings in TLECs might be similar to those in simple thyroid cysts. However, they do not always exhibit the typical sonographic appearance of simple thyroid cysts $[2,5,9-11,15]$. Carney described the cyst as a fluid-filled cavity with a large amount of suspended debris [10]. Lim-Tio et al. described it as a heterogeneous echogenic nodule with a hypoechoic rim [9]. Ahuja et al. reported an echogenic cyst presenting suspended debris associated with a comet-tail artifact [4]. Suzuki et al. reported that half of TLECs appeared as calcified nodules on US [2]. Moreover, TLECs may mimic malignancy on sonography [11].

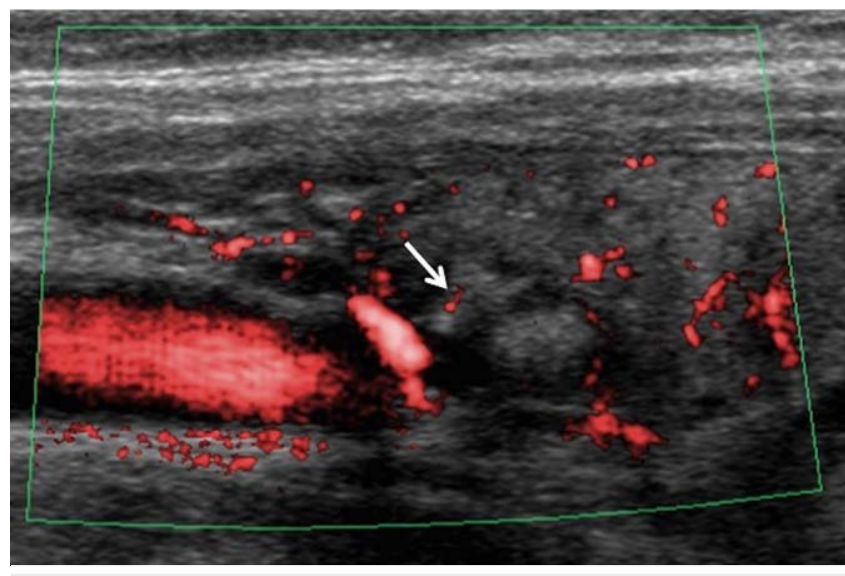

- Fig. 5 Ultrasonography of a thyroid lymphoepithelial cyst, pseudo-solid type. Intranodular vascular flow indicates liquid. (Color Doppler image of B-mode, longitudinal view).

In this study, we classified four types of US findings in TLECs. The cystic type accounted for only half of the TLECs in this study. The others appeared like nodules containing solid components on US, even though the TLECs did not have solid areas or mural nodules. TLECs contained proteinaceous material, cell debris, and/or cholesterol clefts. The contents may influence the US appearance. Similar findings on the internal architecture of cystic lesions have been demonstrated in thyroglossal duct cysts [13].

Interestingly, in this study, $25.0 \%$ of TLECs were the pseudo-calcified type. Kobayashi et al. classified six types of calcifications on US, including punctate microcalcifications, speckled type calcifications, fragmentary type calcifications, massive type calcifications, egg-shell type calcifications, and punctate microcalcifications in the parenchyma [16]. The pseudo-calcified type seen in the present cases was consistent with massive type calcifications. However, histological examination did not reveal calcification. Therefore, the term "pseudo-calcified type" was used. It is unclear why TLECs without calcification present the densely hyperechoic structure with a posterior shadowing artifact. In our study, the pseudo-calcified and cystic type tended to be smaller and larger, respectively. The size of the lesion may be related to its appearance on US. In addition, the structure of the cyst wall, which is composed of a squamous cell lining and lymph follicles, and the intracystic contents may be related to the findings. Recently, Cantisani et al. suggested that Q-elastography is a valuable tool in the characterization of thyroid nodules, and it seems to be more sensitive than contrast-enhanced US [17]. There is a possibility that Q-elastography may be helpful in distinguishing pseudo-calcified TLEC from true calcified nodules.

In conclusion, we examined the US findings for 32 TLECs, and approximately half of them did not exhibit the typical sonographic appearance of simple thyroid cysts. We should be aware that TLECS may mimic calcified or solid nodules on US.

\section{Conflict of Interest}

Authors declare that they have no conflict of interest. 


\section{References}

[1] Carter E, Ulusarac O. Lymphoepithelial cysts of the thyroid gland. A case report and review of the literature. Arch Pathol Lab Med 2003; 127: e205-e208

[2] Suzuki A, Hirokawa M, Ito A, Takada N, Higuchi M, Hayashi T, Kuma S, Daa T, Miyauchi A. Derivation of thyroid lymphoepithelial cysts from follicular cells. Endocr J 2018; 65: 579-586

[3] Watanabe I, Kobayashi K, Yamaguchi M, Kasai M. Multilocular lymphoepithelial cyst in the thyroid accompanied with a minute thyroid carcinoma. Pathol Int 1995; 45: 965-970

[4] Ahuja AT, Chang AR, To E, Pang P, Ching AS, King AD, Metreweli C. Intrathyroidal lymphoepithelial (branchial) cyst: Sonographic features of a rare lesion. AJNR Am J Neuroradiol 2000; 21: 1340-1343

[5] Ryska A, Vokurka J, Michal M, Ludvíková M. Intrathyroidal lymphoepithelial cyst: A report of two cases not associated with Hashimoto's thyroiditis. Pathol Res Pract 1997; 193: 777-781

[6] Louis DN, Vickery AL, Rosai ], Wang CA. Multiple branchial cleft-like cysts in Hashimoto's thyroiditis. Am J Surg Pathol 1989; 13: 45-49

[7] Miyazaki M, Kiuchi S, Fujioka Y. Branchial cleftlike cysts in Hashimoto's thyroiditis: A case report and literature review. Pathol Int 2016; 66: 297-301

[8] Apel RL, Asa SL, Chalvardjian A, LiVolsi VA. Intrathyroidal lymphoepithelial cysts of probable branchial origin. Hum Pathol 1994; 25: 1238-1242

[9] Lim-Tio SW, Judson R, Busmanis I, Zajac JD. An intra-thyroidal branchial cyst: A case report. Aust N Z J Surg 1992; 62: 826-828

[10] Carney JA. Thyroid cysts. Am J Surg Pathol 1989; 13: 1072-1074
[11] Kwak JY, Kim EK, Jung HK, Park HL, Kim GI. Lymphoepithelial cyst of the thyroid mimicking malignancy on sonography. J Clin Ultrasound 2006; 34: 298-300

[12] Wong KT, Ahuja AT, Benign Thyroid Conditions. In Sofferman AR, Ahuja AT. (eds.). Ultrasound of the Thyroid and Parathyroid Glands. New York: Springer; 2012: 64-66

[13] Ahuja AT, King AD, King W, Metreweli C. Thyroglossal duct cysts: Sonographic appearances in adults. AJNR Am J Neuroradiol 1999; 20: 579-582

[14] Wu H, Zhang B, Li J, Liu Q, Zhao T. Echogenic foci with comet-tail artifact in resected thyroid nodules: Not an absolute predictor of benign disease. PLoS One 2018; 13: e0191505

[15] Ahuja A, Chick W, King W, Metreweli C. Clinical significance of the comet-tail artifact in thyroid ultrasound. J Clin Ultrasound 1996; 24: 129-133

[16] Kobayashi K, Fujimoto T, Ota H, Hirokawa M, Yabuta T, Masuoka H, Fukushima M, Higashiyama T, Kihara M, Ito Y, Miya A, Miyauchi A. Calcifications in thyroid tumors on ultrasonography: Calcification types and relationship with histopathological type. Ultrasound International Open 2018; 4: E45-E51

[17] Cantisani V, Consorti F, Guerrisi A, Guerrisi I, Ricci P, Di Segni M, Mancuso E, Scardella L, Milazzo F, D'Ambrosio F, Antonaci A. Prospective comparative evaluation of quantitative-elastosonography (Q-elastography) and contrast-enhanced ultrasound for the evaluation of thyroid nodules: preliminary experience. Eur J Radiol 2013; 82: 1892-1898 